\title{
A PERSONAL, INTERPERSONAL AND PROFESSIONAL LEADERSHIP (PIPL) MODEL OF EXECUTIVE FACILITATION
}

\author{
DEREK VERRIER \\ DAWIE SMITH \\ dpjs@rau.ac.za \\ Department of Human Resource Management \\ University of Johannesburg
}

\begin{abstract}
The focus of this article is to present an empirically-based model of Executive Facilitation based on the Personal, Interpersonal and Professional Leadership (PiPL) paradigm. PiPL is a holistic, wellness perspective that includes the personal, interpersonal, and professional contexts of one's life, and considers the anthropological characteristics and certain existential realities that humankind is confronted with. The executive facilitation model is based upon the current PiPL theoretical framework, emerging streams of organisational theory, the work of classic management gurus, typical problems of executives, and various current executive facilitation models.
\end{abstract}

\section{OPSOMMING}

Die fokus van hierdie artikel is die aanbieding van ' $n$ empiries-gebaseerde model vir die fasilitering van uitvoerende amptenare gefundeer op die Persoonlike, Interpersoonlike en Professionele Leierskapsparadigma (PiPL). PiPL is ' $n$ holistiese, welstandsperspektief wat die persoonlike, interpersoonlike en professionele kontekste van 'n persoon se lewe insluit en wat oorweging skenk aan die tipies menslike asook bestaansrealiteite waarmee die mens gekonfronteer word. Die uitvoerende fasiliteringsmodel is gebaseer op die PiPL kennisraamwerk, op organisasieteorie, die werk van klassieke bestuurskenners, tipiese probleme van uitvoerende amptenare, asook op verskeie fasiliteringsmodelle vir uitvoerende amptenare.

The role of executive facilitation has shifted dramatically in recent years following its humble beginnings in the late 1980s. Its origins can in fact be traced as far back as the 1960s and 70s, when, according to Hudson (1999, p. 4), government and largeorganisation planning was conducted from the top down. Upper management made the decisions, while middle management saw to it that the decisions were carried out. But in the 1970 s and 1980s, it was realised that more flexibility was needed if organisations were to thrive, and the hierarchical control of employees began to give way to trust and collaboration with employees. Widespread training was needed to help every employee think and behave like a leader, but with the emphasis on business performance. Then came seminars on teamwork and empowerment, which made the focus more personal, but training was still focused on immediate corporate issues. The use of consultants added to the movement toward facilitation in that they worked with key corporate figures and system interventions. But these approaches to change were flawed, and therefore didn't last. Then it occurred to many people that if organisations were going to make lasting changes, the individuals working in them must change first. Stephen Covey, author of The Seven Habits of Highly Effective People, was a major proponent in the shift from corporate talk to training highly effective persons. So it was that in the late 1980s, corporate facilitation came on the scene - a field promoting continuous resilience and performance in persons and organisations. The idea was for coaches to work over a period of time with both individuals and the systems in which they functioned. Some of the new emphases that coaches contributed were visionary leadership training, executive facilitation, renewal facilitation, and transition management. A major need was to help individuals and organisations formulate scenarios for the future, given the complexities and speed of change in today's world.

Moving ahead to the present day, it is estimated that 25-40 percent of Fortune 500 companies in the U.S. make use of coaches, while in the UK 70 percent of top companies provide facilitation for their staff (Palmer, 2003, p. 26). In the U.S. there are close to 100 coach training schools. The International Coach

Requests for copies should be addressed to: dawies@uj.ac.za
Federation (ICF), the largest non-profit professional association of coaches worldwide, has more than 5000 members spanning 179 chapters in 30 countries. Alongside this explosion in popularity, there has also been an elevation of the image of the profession in the wider business and academic community. This has seen the establishment of many successful facilitation companies focused on the corporate sector and the establishment of several facilitation courses in respected universities. It is estimated that between 10-20 percent of CEOs of Australian companies have utilised the expertise of a coach. In the U.S. this number was 60 percent, including both mentoring and facilitation programmes. Over 95 percent of people in these programmes found the process to be of value. In Australia today there are over 1000 practicing coaches.

\section{Defining PiPL Executive Facilitation}

For the purposes of this study, the term executive refers to the heads of functional units of an organisation, which includes general managers and upper policymakers through the level of executive directors, managing directors, group executives, chief information officers (CIO), chief operating officers (COO), and chief executive officers (CEO). The key quality that sets them apart from other employees is perspective. The executive must be able to view the world in a much larger sense than others, envisioning global and long-term consequences of any prospect or alternative. This requires an openness to thinking about the world in new ways, the capacity to deal with the ambiguous and undefined, and a willingness to cope with big issues. Finally, executives must possess a strong desire to live and work passionately, to rely on their own judgement, and to exploit their own potential.

In the personal, interpersonal and professional leadership (PiPL) context, preference is given to "Executive Facilitation," rather than "coaching." They should, however, be interpreted as synonyms. As a result of an extensive literature study, the following is offered as a nutshell definition of what Executive Facilitation, from a PiPL perspective, is about:

PiPL Executive Facilitation is an action-learning process that is personalised and developmental in nature, aimed at improving the personal fulfilment and performance of executives through 
enhancing Being (e.g. purpose, meaning, beliefs, values) and Performance (goals, actions, execution). PiPL Executive Facilitation is the art of guiding executives from where they are to where they want to be, creating an awareness of and mastery of the PiPL Pyramid of Leadership and Influence through the three C's, i.e. character, caring and competence. It is aimed at improving executive's quality of life as well as their quality of work, maximising strengths and minimising weaknesses, and unleashing potential. As such, the science of PiPL Executive Facilitation is aimed at the fulfilment, performance and development of the executive in the context of personal, interpersonal and professional effectiveness.

\section{Aim and value of the mode}

The aim of this article is to present an empiricallybased executive facilitation model from a Personal, Interpersonal and Professional Leadership (PiPL) paradigmatic perspective. The model is based upon the existential realities and challenges that confront executives in a South African context. The purpose of such a descriptive model is to organise information and display that information in such a way that the relationships among various elements in some system (in this case executive facilitation) are clarified. The particular uses of the PiPL Executive facilitation model are to:

- provide the PiPL executive facilitator with a theoretical framework for undertaking executive facilitation

- define the typical existential problems and outcomes of PiPL executive facilitation

- provide a graphic understanding of executive facilitation that can be used to manage successful facilitation interactions.

\section{The PiPL Perspective}

The PiPL perspective, developed in the mid-1990s by Professor Dawie Smith of what was formely known as the Rand Afrikaans University, is a relatively new leadership paradigm which acknowledges the holistic nature of human beings. Inherent in the PiPL model is an element of constructive progression. It includes the interdependent nature and the development from personal mastery to interpersonal and consequently professional mastery. Thus, the essence and nature of PiPL can be encapsulated in Personal Leadership, Interpersonal Leadership, and Professional Leadership. These three PiPL pillars, with all their complexities, form the basis of a person's natural reality.

PiPL does not focus primarily on the outer dispositions of a leader (charisma and personality). It strives to discover the essence of an authentic leader and of effective leadership. The Personal Leadership domain of PiPL focuses on authentic selfexpression that creates value (Cashman, 2000, p. 20). It proposes a principle-centred, character-based, inside-out approach to change and leadership (Covey, Merrill \& Merrill, 1994, p. 42). The PiPL perspective reiterates the truth that there are universal laws and principles which govern one's natural and social existence. These principles are an integral part of every individual. Honesty, fairness, dignity, service and excellence are examples of such principles. Personal Leadership and change starts with the individual and is based on the philosophy that 'you' are the only person which 'you' have total control over or can exert control over. So, if change is inevitable, start with yourself, your own attitude and your own (dis)comfort zone.

Personal Leadership in the context of PiPL serves as a foundation for interaction with people. Enduring and happy interpersonal and professional relationships and ultimately leadership and influence, depend on the degree of personal leadership or personal mastery attained. As Covey (1994) says, "It is futile to put personality ahead of character, to try to improve relationships with others before improving ourselves." Personal Leadership requires awareness of and the intention to understand who we really are and what we stand for. It is directed at the discovery of where we want to go. It also includes insight into personal problems of existence and the behaviour and values we choose in coping with these realities. The personal leader is aware of what and how s/he thinks, feels and behaves and how that relates to one's essential self, one's temperament and personality, one's past and present realities, the purpose and meaning of one's life and harmony in one's major life dimensions, i.e. spiritual, physical, emotional, mental, social, career and finance. Authors such as Meyer (1996, p. 2), Smith (1994), Quinn (1996), Pierce and Newstrom (2003), Manning and Curtis (2003), and Skiffington and Zeus (2003), support the views stated above and add to these that an authentic personal leader should demonstrate:

- direction and purpose

- proactive behaviour

- response-ability, i.e. not to blame, to be a victim or to be reactive

- value-driven time and life management

- a burning desire and commitment to achieve one's goals

- determined action to realise one's potential

- principle-centred and an inside-out approach to life

- a win-win attitude to interpersonal relationships

The interpersonal leader would, for example, ask the question: "How can I figure out how to be free to live my life the way I want to live it and still get along well with the people I need?" (Glasser, 1998, p. 5). For decades sociologists and psychologists and even mainstream society aligned themselves with the notion that self-actualisation was the ultimate in human achievement. PiPL however, via its interpersonal and professional wings, embraces the notion of self-transcendence as the pinnacle of optimal fulfilment and achievement. Service, caring and altruism constitute the ultimate virtue in our social reality. In Interpersonal Leadership the emphasis is on the essence of effective relationships, how to be a person of influence and on adding value to others (Smith, 2005b).

Professional Leadership, in the context of PiPL, combines character, caring and a positive attitude with professional competencies. Therefore, the PiPL view of Professional Leadership represents a departure from the traditional view of professional effectiveness. Traditionally, professional leadership was synonymous with status, power and output (production at all cost). Professional Leadership in a PiPL context is based on the precepts of spiritual fulfilment at work, relationship building, teamwork, mutual respect, appreciation, empathic listening, commitment towards a common vision, win-win, synergy, conflict resolution, professional effectiveness and other related principles and values. In the context of change management, PiPL is concerned with change from an outside-in to an inside-out life perspective. This requires a change from a blaming to a personal responsibility attitude, a reactive to a proactive lifestyle, a 'what's-in-it-for-me?' to a 'how can I add value?' approach, a 'want-to-have' to a 'want-to-be' attitude, a critical to a constructive team member, from win-lose to win-win agreements, and lastly from a telling and prescribing to a seeking to listen and understand attitude.

Hence, a PiPL perspective entails a study of the awareness of the fundamental problems facing mankind in the context of their personal realm, their relationships with people, and their professional environment. PiPL confirms the ability and potential of all human beings, irrespective of race, colour, gender or creed. Humans can excel and succeed, in all dimensions of life - be it spiritually, physically, emotionally, intellectually, or in their relationships with people. Their freedom of choice, along with willpower, can unlock inner potential. The source of, and the utilisation of one's potential, can be viewed from a theocentric or a humanistic perspective. Whichever one chooses is a personal choice. PiPL operates 
from generic anthropological and universal life principles which are true for all people irrespective of their beliefs or religious views. Thus, PiPL has very specific and enduring phenomenological, anthropological, psychological, and philosophical foundations.

The Helping Professions can be divided into three broad approaches:

- Therapy: includes psychiatry, psychotherapy, and trauma counselling. The focus is more on the past and the present, on serious problems, and on the unconscious. It is generally long term and it requires psychiatric or psychological background (the Professionals).

- Counselling (and Facilitation): involves well-adjusted people, and uses approaches such as NLP, Albert Ellis' REBT, Carl Rogers' Self Theory, The Franklin Reality Model, William Glasser's Choice Theory, Viktor Frankl's Logotherapy, and conventional Mentoring approaches.

- Facilitation, among others, is directed at finding purpose, personal growth, potential realisation and quality relationships. Approaches such as Life Coaching (McGraw, 2001) and Lifeskills Coaching (Nelson-Jones, 1997) are included in the facilitation approach.

\section{The PiPL Pyramid of Leadership}

With regard to these, PiPL concerns itself with facilitation which is primarily a present- and future-oriented form of intervention. The aim of a PiPL approach, is:

Personal Mastery: Potential realisation, finding purpose and meaning in life, total wellness and balance in one's life dimensions.

Interpersonal Mastery: Understanding and living the essence of sound relationships.

Professional Mastery: Finding fulfilment in work, responsibility, commitment, acknowledgement, performance and an effectiveness orientation.
The PiPL Pyramid of Leadership and Influence shown in Figure 1 , crystallises into three critical tenets: Character, Caring and Competence

The three sequential Leadership Roles can also be termed Personal, Interpersonal, and Professional Leadership. These sequential roles, also expressed as Modelling, Mentoring and Managing result in the fruits of personal Responsibility, Sound Relationships, and Return on Investment (ROI), respectively.

Personal leaders, being proactive by nature, focus their efforts in the Circle of Influence. They work on things they can do something about. The nature of their energy is positive, enlarging and magnifying, causing their Circle of Influence to increase (Covey, 1994, p. 83). Reactive people, on the other hand, focus their efforts in the Circle of Concern. They focus on the weakness of other people, the problems in the environment, and circumstances over which they have no control.

\section{Smith's Life Dimensions Model}

PiPL is also based on Smith's Life Dimensions Model. Four of these dimensions are internal and four are external. The internal life dimensions are the Spiritual, the Physical, the Emotional and the Mental. The external life dimensions are the Social, one's Career, Finance and the Ecological environment.

These dimensions of life and wellness define one's uniqueness, and help us understand who we are. The spiritual dimension is at the centre of a person's life and totality. As human beings we are alive because the spiritual essence within us is naturally attracted to life in material form (Prescott, 2000, p. 37). The quality of life depends on the ability to balance the internal life dimensions of life with the external life dimensions. These life dimensions are of critical importance in developing an individual facilitation model for executives. It will therefore serve a purpose to consider these dimensions separately in order to understand their significance in our lives. It must be pointed

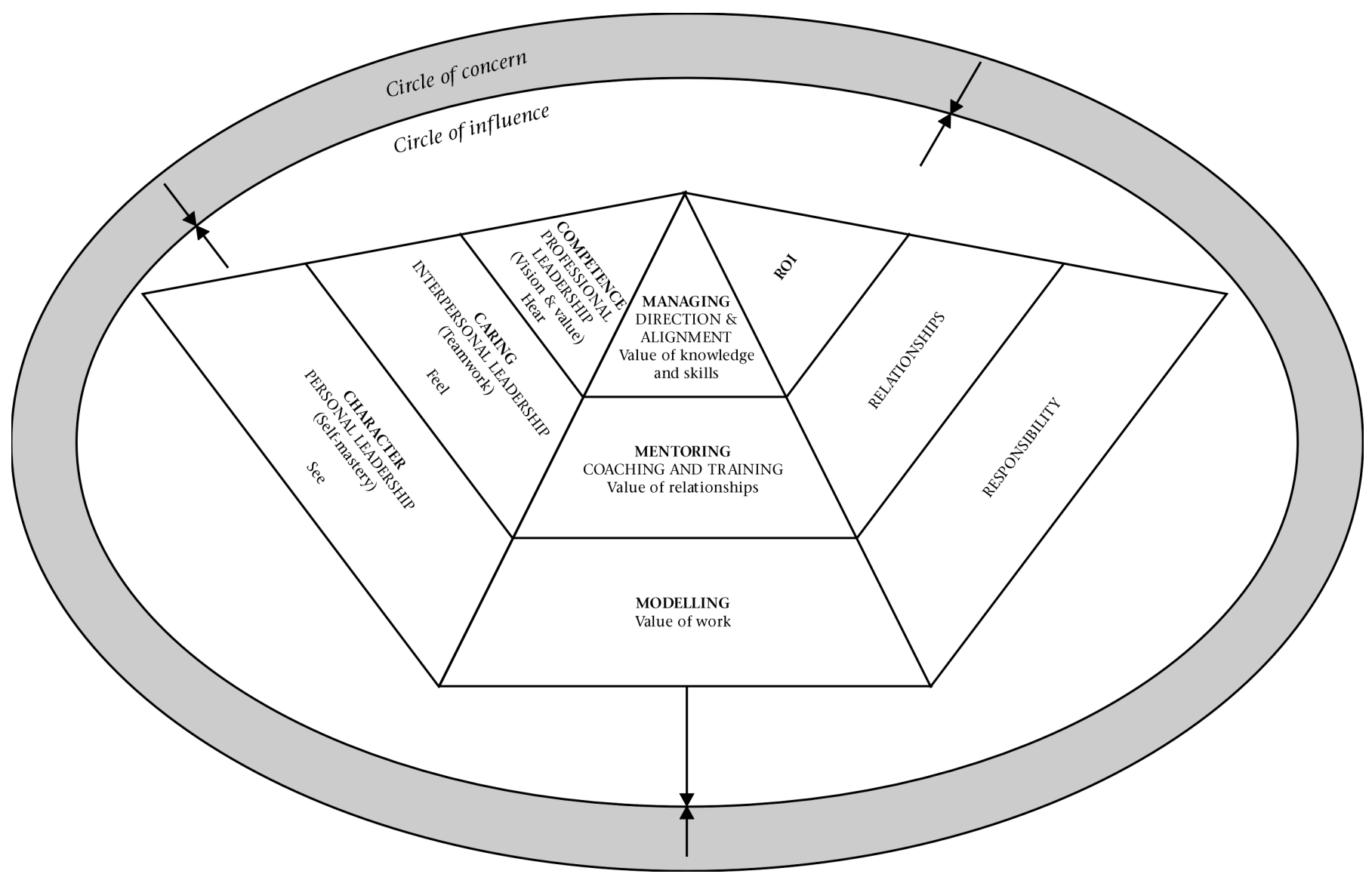

Figure 1: The PiPL Model - The Pyramid of Leadership and Influence 
out that these dimensions are not separate compartments of life, but form part of a highly interrelated whole.

- The Spiritual Dimension can be defined, among others, as a search for purpose, meaning, value, inner wholeness, connectedness, harmony, love, morality, beauty, wisdom, hope, vitality and gratitude (Zohar and Marshall, 2000; Zohar and Marshall, 2004; Pearsall, 1999; Peirce, 1997; Frankl, 1984; Temple-Thurston, 2003; Smith, 2005c). Our spiritual dimension is considered to be our ultimate, or core dimension.

- The Physical Dimension: This dimension refers to the optimal wellness and health of the physical systems in the body, as well as its effective functioning as an integrated whole. The physical dimension includes physical health, vitality and energy, cardiovascular fitness, muscle strength, endurance and flexibility, a healthy diet and theories of biomarkers of ageing (Corbin \& Lindsey, 1997).

- The Emotional Dimension: This dimension refers to the ability to be aware of and be in control of one's emotions, to be aware of, understand and be sensitive to others' emotions and to express one's feelings in an accountable way (Caruso and Salovey, 2004; Calhoun and Solomon, 1984).

- The Mental Dimension: The mental dimension must be distinguished from the intellectual dimension. It, among others, refers to awareness, consciousness and power of thought (Murphy, 1993; Witz, 1998).

- The Social Dimension: As social beings it is a fundamental need of a person to be with and to have meaningful relationships with other people. A person's happiness, moods, and self-esteem are all influenced to a large degree by the relationships they hold with others. Key elements of relationship mastery, or what could also be called Interpersonal Leadership, include one's Circle of Influence, trust and trustworthiness, communication, doing to others as one would have done to oneself (the Golden Rule), and empathy.

- The Lifestyle, Finance and Career Dimension: Lifestyle refers to one's daily patterns of behaviour or ways one typically lives. Career is a person's work life and how it influences one's daily living. Finance is the ability to balance income and expenses, and in the process maintain a respectable meaningful life (Robbins, 1992).

- Ecological environment: As human beings we are living organisms in relation with each other and our environment. The reciprocal impact of human beings on their environment has become a major area of research. Human behaviour and wellness can only be understood by considering this factor as central in human endeavour.

In addition to the life dimension, the PiPL paradigm is also founded, or presupposed, in existential and anthropological realities. Existential realities refer to problems of existence and finding ways to cope. Anthropological realities refer to that which is typically human. These realities help one better understand the human condition. PiPL has roots that go beyond the superficial and the mundane by getting at the root of human nature. Besides the mentioned realities there are assumptions that form critical links in the chain defining PiPL. Two such central, elementary assumptions include:

- Life has a purpose. As such it is necessary for human beings to detect their unique life purpose, and to develop a strategy that will ensure that they are able to live on that purposeful path.

- An increasing number of people experience an existential vacuum: The majority of people, especially in the Western world and in big cities, have become disconnected from their spiritual core, and hence experience a pervasive sense of emptiness and meaninglessness.

This is where the strength of the PiPL executive facilitation model lie and why it has been necessary to develop a new model in the first place - that is why, as Victor Hugo put it, "it is an idea whose time has come." PiPL is a holistic paradigm that deals with the essence of who and what we are. The model's existence is underpinned by the fundamentals of human nature. And after all, when it comes right down to it, at the core most organisational problems have common roots - misunderstanding human/individual nature - i.e. they lack a whole-person paradigm. After all, individual behaviour is merely collectivised in organisations. The key therefore to understanding organisational behaviour is not to study organisational behaviour, per sé. It is to study and understand human nature. For once one understands the fundamentals of human nature, one possesses the key to unlock the potential inside of people and organisations (Covey, 2004).

There are also a number of facilitation approaches that are used by PiPL executive facilitators in applying the PiPL Model when addressing the typical personal issues which they are confronted with in the course of facilitation interventions. Some of these approaches are as follows:

- Systems-Centred Counselling for individuals (Rosenthal, 1998:25)

- Rational Emotive Behaviour Therapy (REBT) as developed by Albert Ellis (1999)

- Reality Therapy and Choice Therapy: Reality therapy is based on William Glasser's (1998) "Choice Theory" that rests on the principle that all of our motivation and behaviour is an attempt to satisfy one or more of our five universal human needs (survival; health and reproduction; love and belonging; self-worth/power; freedom; fun and enjoyment), and that we are responsible for the behaviours we generate or choose. The core idea is that regardless of what may have happened to a person, or what they may have done, or how their needs may have been violated in the past, they can re-evaluate their current reality and choose behaviours that will help them to satisfy their needs more effectively now and in the future.

- Life Counselling (Richard Nelson-Jones, 1997)

- Carl Rogers' Person-Centred Counselling (Rogers \& Sanford, 1985)

- Viktor Frankl's existential counselling (Logotherapy) (Havenga, 1974)

- The Franklin Reality Model (Smith, 1994): similar to REBT, it offers a visual picture of why we behave the way we do. It helps us see a clear connection between our beliefs and our behaviour. It helps us evaluate our beliefs before they affect our behaviour.

\section{METHODOLOGY}

The methodological approach to this study was primarily non-empirical, but was supported by limited empirical interviews. Thus the central approach was "theory building and model building," described by Mouton (2001, p. 176) as one aimed at developing new models and theories to explain particular phenomena. Further, a descriptive research strategy was employed in conjunction with a hermeneutic, phenomenological approach. The strategy of inquiry was phenomenological as the 'essence' of human experiences concerning facilitation needs, as described by participants in the study has been identified (Creswell, 2003, p. 15).

A purposeful (convenience) method of sampling was used in this study. Purposeful sampling is based on the assumption that "one wants to discover, understand, gain insight; therefore one needs to select a sample from which one can learn the most" (Merriam, 1988 p. 48). The subjects were chosen from a specific target group whose opinions and ideas are particularly germane to the study. The initial target for number of interviews was stated as seven, but in getting to a saturation point where it was felt that additional interviews would not have added further value, five interviews were seen as conclusive. 
The research group consisted of five large-organisation executives from both the public and the private sector. All the executives occupied senior positions in their respective organisations, and can hence be considered, using the terminology of Charan, Drotter \& Noel (2001), to be either Enterprise Managers or Group Managers. In selecting participants, the researchers were mindful of Miles \& Huberman's (1994) four considerations: the setting (where the research will take place), the actors (who will be interviewed), the events (what the actors will be interviewed doing), and the process (the evolving nature of events undertaken by the actors within the setting).

Specific research methods that were utilised included concept analyses, a literature study, and one-onone interviews. A concept analysis is used when the meaning of a concept needs clarification or when the different views of experts about the concept are considered (Mouton, 2001, p. 175). A literature review involves the process of discovering related and relevant previous work from a range of sources such as textbooks, scientific journals, theses, dissertations, magazines and newspapers (Melville \& Goddard, 1996:18). In addition to the data collection procedures described above, unstructured one-onone interviews were also used in the empirical element of the study.

\section{RESULTS}

In developing a model for executive facilitation an attempt was made to find empirical content for it, and if fair enough saturation was found then the most important factors in an executive's life would have been identified. It is important to reiterate that being a qualitative study, the focus was on the subjective perceptions and experiences underlying people's behaviour and feelings. The issues identified in executive's lives, were rated by the study's participants as a 1,2 , or 3, depending on their own experience of the issue. Based on these ratings, those items that appear to be problematic to the sample group (i.e. where two or more people experience some difficulty with the issue) are indicated in Table 1 by an asterisk $\left({ }^{*}\right)$. The other less critical issues are included because they relate to the PiPL paradigm and model and they serve to enrich the theory presented thus far.

Naturally these issues, and the many others that executives are confronted with, will differ from one executive to another in terms of the degree to which they struggle with them. The results above, relate purely to the small sample group of this study. What's important is not so much the quantitative ratings that came out of the study, as this could not be generalised to the executive population as a whole, but rather in recognising that there are considerable challenges that may well need to be dealt with one way or another through the various tools that form part of an executive facilitator's armoury. Perhaps also, one should remember that in the executive facilitating arena it is not necessarily about having all the answers to these issues, or about being able to give definitive remedies to resolve them, but rather it's about the ability to ask the right questions and present alternative perspectives, thereby leading executives to their own wisdom and solutions.

With the myriad challenges and dilemmas faced by executives, it is obvious that a facilitator needs to have the tools and be well equipped to deal with them. A sound facilitation process and model are just two such tools that need to be understood and applied when appropriate. Such tools need to be capable of bringing about real and deep change in an executive, in situations where deeply-entrenched, self-defeating behaviours have become highly resistant to change.

Russian writer Ivan Turgenev wrote in Fathers and Sons in 1862, "A picture shows me at a glance what it takes dozens of pages of a book to expound." And this is one of the major benefits of a model. Models illustrate the essential details of some system or set of variables in a way that written procedures cannot. When constructed properly, they can replace many pages of words.

\section{TABLE 1}

THE CHALLENGES AND STRUgGLES EXECUTIVES FACE

\begin{tabular}{|c|c|}
\hline & PERSONAL CONTEXT \\
\hline No. & Description \\
\hline & Self-confidence and assertiveness \\
\hline $2 .^{*}$ & Continually learning, growing and improving \\
\hline 3.* & Worry about retirement \\
\hline & Spirituality \\
\hline $5 . *$ & Time management; over-commitment; handling stress and burnout \\
\hline 6. & Being authentic \\
\hline 7. & Health Problems/Wellness \\
\hline 8. & Depression \\
\hline
\end{tabular}

\begin{tabular}{l}
\hline \multicolumn{1}{c}{ INTERPERSONAL CONTEXT } \\
\hline 9.* $\begin{array}{l}\text { Relationships and family; balancing life tasks of love, work and } \\
\text { friendship }\end{array}$ \\
10. Communication ability; listening skills \\
11. Building relationships; trust and mutual respect
\end{tabular}

PROFESSIONAL CONTEXT

12. ${ }^{*}$ Being strategic in the midst of details (phone, fax, email)

13. * Succession planning

14. * Managing conflict; dealing with emotions

15. ${ }^{*}$ Corporate financial health; organisational performance

16. ${ }^{*}$ Delegating and empowering others to solve problems and seize opportunities

17. * Letting go of control

18. Self-doubt about leadership abilities

19. Retaining and developing key contributors

20. Developing leaders

21. Performance of self and team; mobilising commitment

22. Maximising staff effectiveness while avoiding micromanagement

23. Balancing work and personal life (balancing head, heart and hand, self-care).

24. Helping others to grow; unleashing creativity, resourcefulness and talent of workforce

25. Developing and sharing vision

26. Building an organisational culture characterised by flexibility and continuous improvement

27. Turning a mission statement into a constitution

28. Creating team spirit among departments amidst conflicts, politics, and hidden agendas

29. Feeling that work is meaningless; job not leading anywhere; nothing to strive for anymore; they ask "Is this all there is to life?"

The PIPL Executive Facilitation Model, shown in Figure 2, is based upon a holistic, integrated perspective of the executive arena, beginning with personal mastery, followed by relationship-, managerial-, and organisational mastery (in that order). 


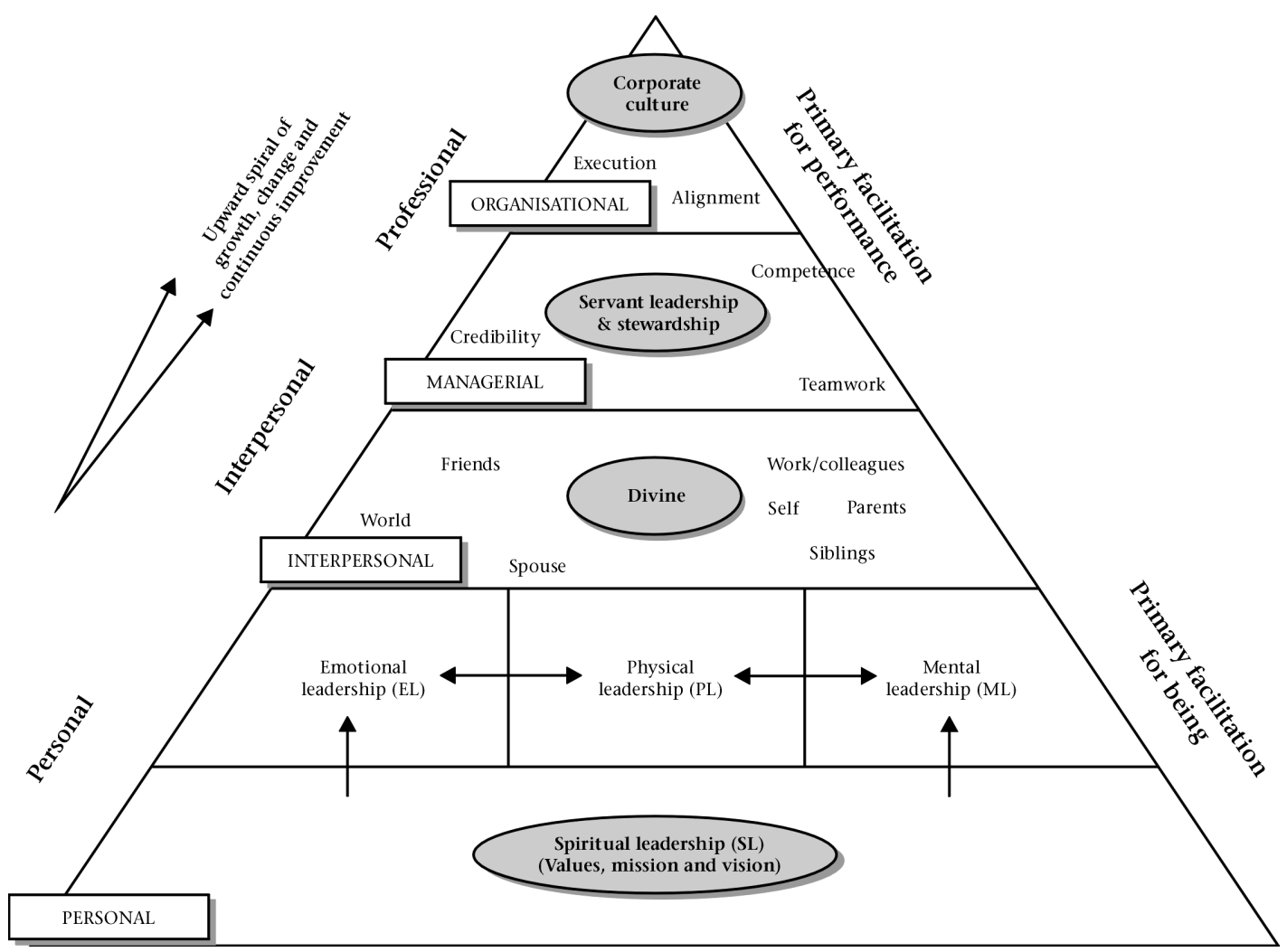

Figure 2: The PiPL Executive Facilitation Model

\section{DISCUSSION}

\section{Interpretation}

In the private or public sector, in big business or small, a distressed executive, or a healthy effective executive, will create and sustain superior performance and wellness (quality of life) if he or she is facilitated by means of the PiPL model at the appropriate place in the facilitation process. The model has various salient features that are as follows:

(a) The model indicates the three contexts of leadership that embrace the life of an executive: personal, interpersonal and professional (which in turn has the sub-contexts of the managerial and the organisational). Personal being a person's relationship with him- or herself; interpersonal being relationships and interactions with others; managerial being one's responsibility to get a job done with others; organisational being the need to organise people - to recruit them, train them, compensate them, build teams, solve problems, and create aligned structure, strategy and systems (Also see Table 2).

(b)The model espouses the view that effectiveness as a leader in the professional realm has as precondition the "private victory", which essentially equates to significant growth at a personal level, thereby yielding an abundance of integrity, maturity, character strength and emotional fortitude. As Charles Dickens once said, "Every man, however obscure, however far removed from the general recognition, is one of a group of men impressible for good, and impressible for evil, and it is in the nature of things that he cannot really improve himself without in some degree improving other men." Thus, a leader, whose behaviour and attitude impact upon the lives of many constituents, is compelled to strive for continuous and never-ending improvement in the various facets of his personal life.

(c) The essential elements of the personal realm include awareness and progressive mastery in the following areas: Spiritual Leadership (SL), Physical Leadership (PL), Emotional Leadership (EL), and Mental Leadership
(ML) (Smith, 2005b). As stated earlier, spiritual leadership is at the centre of the executive's life and totality, and therefore forms his ultimate or core dimension. For this reason, SL is indicated on the model as the foundation and as a binding and unifying component of personal mastery. Toward that end, the articulation and commitment to a personal value system, mission, and vision are crucial.

(d)Mastery at the interpersonal, or relationship level, includes an executive's roles in relationship with: God, the world, spouse, friends, siblings, parents, work colleagues, and self. The very essence of all of these relationships, according to Smith (2005a), is: acceptance, authenticity and adding value. Facilitation at this level would focus on inculcating these qualities into the character and value system of the executive.

(e) Facilitation at the first two levels, the personal and interpersonal, is concerned primarily with Facilitation for Being (the Inner Work) - that is, facilitation for resilience, beliefs, values, self-esteem, courage, purpose, and centering. However, facilitation for being is also important at the other levels, just as Facilitation for Performance is not exclusive to the upper levels of leadership (Hudson, 1999, p. 20).

(f) The crux of the managerial level is Servant Leadership and an associated paradigm of Stewardship. Servant leadership, which would be a natural and congruent outgrowth of fundamental character strength and internal security, gives a leader the capacity to be open to developing and honing the other skills and competencies necessary at this level (Wilson, 1998).

(g) Credible Leadership embodies qualities such as displaying appropriate personality traits and characteristics; displaying appropriate behaviours and attitudes; being principlecentred; being values-centred; having integrity; being authentic; leaving a legacy, spiritual leadership (Smith, 2005b), and Managing by Walking Around (MBWA). Peters \& Austin $(1985$, p. 31) describe this as being in touch with customers, suppliers, and one's people. It facilitates innovation, and makes possible the teaching of values to every member of an organisation. It involves listening, facilitating, teaching and reinforcing values. Its effectiveness is many times that of a formal speech. 
TABLE 2

Characteristics OF THE PIPL EXECUTIVE FACILITATION MODEL

\begin{tabular}{|c|c|c|c|c|c|}
\hline Leadership Role & $\begin{array}{l}\text { Fundamental } \\
\text { Composite } \\
\text { Principle }\end{array}$ & $\begin{array}{l}\text { Human System(s) } \\
\text { being Coached }\end{array}$ & Overt Goals/Outcomes & Covert Goals/Outcomes & Overall Goals/Outcomes \\
\hline Organising & Alignment & Work & $\begin{array}{l}\text { - } \quad \text { Community } \\
\text { - } \quad \text { Shared mission and vision } \\
\text { - } \quad \text { Shared values } \\
\text { - Tolerance } \\
\text { - The Golden Rule } \\
\text { - } \quad \text { "Vital" Culture } \\
\text { - Close to the customer }\end{array}$ & $\begin{array}{ll}- & \text { Purpose and meaning } \\
- & \text { Security } \\
- & \text { Social mindedness and } \\
& \text { caring }\end{array}$ & 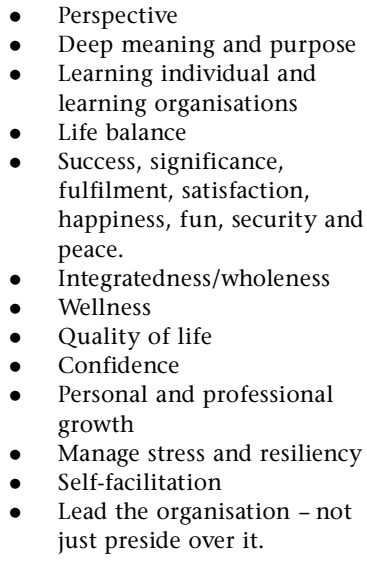 \\
\hline $\begin{array}{l}\text { Organising and } \\
\text { Teaching }\end{array}$ & Empowerment & Work & $\begin{array}{ll}\text { - } & \text { Credibility (Managing By } \\
\text { - } & \text { Salking Around - MBWA) } \\
& \text { stewant leadership and } \\
\text { - } & \text { Competency } \\
\text { - } & \text { Defining reality } \\
& \text { accurately on } 4 \text { levels } \\
\text { - } & \text { Balance path-finding, } \\
& \text { decision-making, and } \\
& \text { implementation } \\
\text { - } & \text { Presencing }\end{array}$ & $\begin{array}{ll}\text { - } & \text { Trust } \\
\text { - } & \text { Synergy (dialogue) } \\
& \text { development } \\
\text { - } & \text { Heightened level of self, } \\
\text { energy and commitment } \\
\text { - } \quad \text { Execution } \\
\text { - Link to highest future } \\
\text { - } \quad \text { Eossibilities } \\
\text { Ethical decision making }\end{array}$ & \\
\hline Mentoring & Trust & $\begin{array}{l}\text { Couples } \\
\text { Family and Friends } \\
\text { Community } \\
\text { Colleagues } \\
\text { Subordinates } \\
\text { ManagerTeam }\end{array}$ & 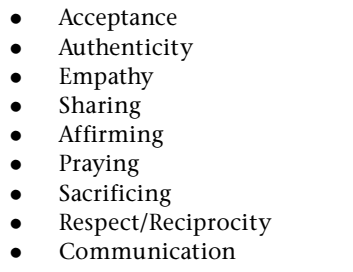 & $\begin{array}{ll}\text { - } & \text { Trust } \\
\text { - } & \text { Synergy } \\
\text { - } & \text { Connecting } \\
\text { - } & \text { Added value } \\
\text { - } & \text { Feeling valued } \\
\text { - } & \text { Feeling acknowledged }\end{array}$ & \\
\hline Modelling & Trustworthiness & Personal Care & $\begin{array}{ll}\text { - } & \text { Balance } \\
\text { - } & \text { Self-examination } \\
\text { - } & \text { Self-awareness } \\
\text { - } & \text { An abundanciple-centredness } \\
\text { - } & \text { State of being open } \\
\text { - } & \text { Sense of personal mission } \\
& \text { and vision }\end{array}$ & $\begin{array}{ll}- & \text { Character } \\
- & \text { Maturity } \\
- & \text { Integrity } \\
\text { - } & \text { Emotional fortitude }\end{array}$ & \\
\hline
\end{tabular}

(h)Competent leadership embodies, among others, flexibility in leadership style; big picture thinking; value-adding; measuring success (via the balanced scorecard); strategic thinking; fostering creativity; leading change; leading performance; and valuing human capital (i.e. empowering, delegating, and intrinsically motivating employees) (Smith, 2005b).

(i) Teamwork includes understanding and applying the five teamwork dysfunctions and the five steps to developing a cohesive executive team, as defined by Lencioni (2002).

(j) The need for a leader to define reality for his people on four levels - events, patterns of behaviour, systemic structures, and a "purpose story" (Senge, 1990, p. 353) - is an essential, yet often neglected, element at the managerial level.

(k)If one were to reduce each level of leadership seen in Table 2 to a fundamental, composite principle (albeit that in reality each level includes numerous overlapping natural laws), it would be trustworthiness at the personal level, trust at the interpersonal level, empowerment at the managerial level (which translates into ownership), and alignment at the organisational level (Covey, 1992). Alignment means ensuring that the style of the people and the structures and the systems one sets up are totally in alignment, and that individual mission statements are also aligned with the organisation's mission statement (e.g. if one says one values innovation, does one reward people for lock-step conformity? If one says one values the long-term, is everything focused upon the short-term?) (Verrier, 2002, p. 58). Each principle builds upon the one before it - i.e. each is necessary but insufficient - so one will not achieve alignment without first empowering people; one can not empower people without there being a high degree of trust in relationships; and trust will not exist if one or other of the parties is fundamentally untrustworthy.

(1) The fruit of getting all of this right by "working" at all four levels and embracing and striving for mastery of the competencies at each level, is a strong and viable corporate culture at the organisational level. If one considers the way in which Louis V. Gerstner (2002) transformed the culture at IBM in the early 1990s, this point becomes clearer. He observed, "You can't lead a revolution from the splendid isolation of corporate HQ. You can't simply give a few speeches and write a new credo and expect a new culture 
has taken hold. You can't mandate, or engineer it. You can only create the conditions. You can provide incentives, define market-place realities and goals, but then you have to trust. In the end management doesn't change culture; management invites the workforce itself to change the culture." He reduced IBMers to believe in themselves again; that they have the ability to determine their own fate and that they already knew what they needed to know. He got them to be hungry, collaborative, self-starters. He needed to get them to listen to him, where they needed to go, to follow him there, but he also needed them to stop being followers. This is not a logical, linear challenge - it is counter-intuitive. It is centred in social cues and emotions, rather than reason. Thus, transforming a dysfunctional culture takes at least 5 years. And the CEO has to be a leader - he has to be upfront and outspoken about what he is doing, he has to get the TMT to join him, he has to talk directly about culture, behaviour and beliefs. He can't be subtle.

(m) An integral part of the right culture is creating a sense of intrinsic motivation for employees; meaning that they are energised by the work itself and they feel passionate about it. They see their work as making a significant difference and they believe in what they are trying to accomplish. There is strong evidence of the four intrinsic rewards (i.e. a sense of meaningfulness, choice, competence, and progress), and their associated building blocks, in such a culture (Thomas, 2000).

(n) The same argument holds for the ability to get things done, or Execution. This is another characteristic of effective leaders who have worked at all four levels of the model, who have embarked upon an upward spiral of growth, change, and continuous improvement - they get things done through others. After all, an organisation is nothing more than the collective capacities of its people to create value, and a good leader is able to tap into individual capacities, and integrate them, in pursuit of their company's "purpose story."

(o)It is essential to work at all four levels of the model. Even though it is easy, and sufficient to work at one or two or even three levels, in the long-term it will not take, it will not work. As Gandhi once said, "A person cannot do right in one department of life, whilst attempting to do wrong in another department. Life is one indivisible whole." Drawing upon this quote, we can see that a balanced, inclusive approach that addresses all "departments" (levels) is needed for real and deep change to occur in individuals and in organisations. As Goleman, Boyatzis \& McKee (2002, p. 291) state, most executive education and leadership development efforts fall far short of the mark, not only because of how they are done, but also because of what they do not do. Even the best development processes will not help to change the organisation if they focus only on the person and do not take into account the power of the emotional reality and the culture.

(p)Indicated in Table 2 following the model are the goals (or outcomes) at each leadership level. The goals are classified as being overt, covert or overall. For any goal that is pursued, there must be a clearly articulated strategy bridging the client with the goal, as well as a clearly articulated action plan bridging each strategy in turn. There must also be a solution-focus in setting and committing to stretch goals.

(q)The overall outcomes of facilitating the PiPL model with either a functional or a dysfunctional executive, would include one or more of the following:

- Giving him new and useful perspectives on things that matter.

- A deeper sense of meaning and purpose in life.

- Becoming a life-long learner in the context of a learning organisation.

- An enhanced ability to balance work and personal life.
- An enhanced sense of success, significance, fulfilment, satisfaction, happiness, fun, security, and peace.

- Wholeness, or integratedness of all parts of their nature.

- An enhanced sense of wellness.

- Improved quality of life.

- Confidence.

- To enter a virtuous cycle of personal and professional growth.

- Resiliency and greater capacity to manage stress.

- Self-facilitation.

- To become a better leader, and not merely a 'presider' over a company.

\section{Conclusion}

One can see then that the PiPL approach deals with the personal side of leadership. PiPL recognises that life can be hard. It acknowledges that one must be tough to meet life on its own terms. The role of PiPL in business and in public life is to support those who make the important decisions and hold the big accountabilities, those who require the big buttresses in managing the harshness of life - and the need they themselves have to be fortified for making the hard decisions - to defend their hard choices, and to assuage their consciences.

Koestenbaum (1991, p. 4) distinguishes between the strategic and personal sides of leadership - one masculine, the other feminine; one left-brain, the other right-brain; one toughminded, the other tender-minded. Strategic thinking deals with external alliances, product positioning, and organisational structure. Strategies are the province of the natural, life, and behaviour sciences. The personal side concerns motivation, character, maturity, will power, freedom, meaning, creativity, ethics and values, culture, responsibility and accountability, loyalty, commitment, selfsacrifice, love, courage, genius, and other qualities. These virtues are in the province of the humanities (such as philosophy, theology, literature, and the arts).

It is, however, important to acknowledge that there has to be an accountability side to the people-orientation advocated by PiPL: one needs to measure and be performance-oriented, as a result of mutually high expectations and peer review, rather than from complicated control systems and authoritarian managers. It is the feeling of being needed that produces high expectations and high performance, especially when your peers have those high expectations of you. People like to compare themselves to others, and they also like to perform against standards - especially if they had a role in setting the standard, and if it is achievable (Peters \& Waterman, 1982, p. 240).

From the research done in the PiPL field and the PiPL perspective itself, the evidence is overwhelming that PiPL has a significant contribution to make in the executive arena through facilitation interventions that promote more balanced and better performing leaders. This is self-evident as PiPL deals with it all (i.e. there is an ecological element to it). It looks beyond the traditional, parochial, management focus of business (although it acknowledges that that is important too), and focuses on the human issues, as it believes that that is where real and sustainable growth and change lie. But at the same time, it knows its own bounds and recognises those things that it is unqualified to address - topical content taught by experts such as strategy, marketing, finance, and other abstractions. As important as these academic areas are, none of them add up to transformation of a person or of a company. This can only occur if one adopts an integrated, holistic approach that permeates every level of the organisation: individuals, relationships, teams, and the organisation's culture.

An important element of the PiPL perspective is the psychodynamic influences of leaders. According to Nelson- 
Jones (1997) the term "psychodynamic" refers to the transfer of psychic or mental energy between the different structures and levels of consciousness within people's minds. Thus, it is about the importance of unconscious influences on how people function and in making the unconscious become conscious. These influences can all have a dramatic impact on organisational performance. They can lead to impulsive decision making, morale problems, inadequate leadership, and untenable strategies and structures. Organisational consultants and facilitators simply cannot afford to ignore these factors as contributors to the problems that they so often struggle with. Specific problems in firms often stem directly from the long-standing intrapsychic problems of their managers. Certain measures only address symptoms without getting at their root causes. They are therefore unlikely to be of much use. Sometimes the only way to change the organisation's behaviour is to change the behaviour of its principle actors.

Just as it is hazardous to be too shallow in diagnosing and treating organisational problems - looking at surface phenomena and ignoring the underlying psychodynamic influences - it is also unwise to go to the other extreme. Not all organisational problems have their roots in widespread or complex psychopathology. Many problems may be the result of simple ignorance - just the lack of knowledge and competence by key decision makers about the nature of their business. In the final analysis, we have to keep in mind that it is the ability to find simplicity within complexity that characterises effective intervention. That is why it is important to try to implement a simple solution first - to address only the objective problems (Kets de Vries \& Miller, 1984).

"Our chief want in life is someone who will make us do what we can." - RALPH WALDO EMERSON

\section{REFERENCES}

Calhoun, C. \& Solomon, R.C. (1984). What is an Emotion? Classic Readings in Philosophical Psychology. New York: Oxford University Press.

Caruso, D.R. \& Salovey, P. (2004). The Emotionally Intelligent Manager. San Francisco: Jossey-Bass.

Cashman, K. (2000). Leadership from the inside out. Provo: Executive Excellence Publishing.

Charan, R., Drotter, S. \& Noel, J. (2001). The leadership pipeline: How to build the leadership-powered company. San Francisco: Jossey-Bass.

Corbin, C.B. \& Lindsey, R. (1997). Fitness and wellness. USA: Brown \& Benchmark.

Covey, S.R. (1994). The 7 habits of highly effective people: Powerful lessons in personal change. New York: Simon \& Schuster.

Covey, S.R. (1992). Principle-centered leadership. New York: Simon $\&$ Schuster.

Covey, S.R., Merrill, A.R. \& Merrill, R.R. (1994). First things first. London: Simon \& Schuster.

Covey, S.R. (2004). The 8th habit: From effectiveness to greatness. London: Simon \& Schuster.

Creswell, J.W. (2003). Research design: Qualitative, quantitative, and mixed methods approaches. Second edition. California: Sage Publications.

Ellis, A. (1999). How to control your anger before it controls you. Toronto: Carol Publishing Group.

Frankl, V.E. (1984). Man's Search for Meaning. New York: Simon \& Schuster.

Gerstner, L.V. (2002). Who says elephants can't dance? Inside IBM's historic turnaround. USA: Harper Collins Publishers Inc (Audio).

Goleman, D. \& Boyatzis, R. \& McKee, A. (2002). The new leaders. Great Britain: Time Warner Paperbacks.
Glasser, W. (1998). Choice theory. New York: HarperPerennial.

Havenga, A.A. (1974). Antropologiese onderbou van Logoterapie. Unpublished D-Phil. Thesis, Pretoria: University of Pretoria.

Hudson, F.M. (1999). The Handbook of coaching: A comprehensive resource guide for managers, executives, consultants, and human resource professionals. San Francisco: Jossey-Bass Publishers.

Kets de Vries, M.F.R. \& Miller, D. (1984). The neurotic organization: Diagnosing and changing counterproductive styles of management. San Francisco: Jossey-Bass.

Koestenbaum, P. (1991). Leadership: The Inner Side of Greatness. San Francisco: Jossey-Bass Publishers.

Lencioni, P. (2002). The five dysfunctions of a team: A leadership fable. San Francisco, California: Jossey-Bass.

Manning, G. \& Curtis, K. (2003). The Art of Leadership. Boston: McGraw-Hill.

McGraw, P.C. (2001). Self Matters. New York: Simon \& Schuster Source.

Melville, S. \& Goddard, W. (1996). Research methodology. Cape Town: Juta \& Co Ltd.

Merriam, S.B. (1988). Case study research in education: A qualitative approach. San Francisco: Jossey-Bass Publishers.

Meyer, P.J. (1996). Effective Personal Leadership. USA: Leadership Management International, Inc.

Miles, M.B. \& Huberman, A.M. (1994). Qualitative data analysis. Second edition. London: Sage Publications.

Mouton, J. (2001). How to succeed in your master's and doctoral studies: A South African guide and resource book. Van Schaik Publishers: Pretoria.

Murphy, J. 1993. The power of your subconscious mind. New York: Pocket Books.

Nelson-Jones, R. (1997). Counselling and Helping Skills: How to Use the Lifeskills Counselling Model. London: Cassell.

Palmer, B. (2003). Maximizing value from executive coaching. Strategic HR Review, Sep/Oct 2003, (2), 6.

Pearsall, P. (1999). The Heart's Code. New York: Broadway Books.

Peters, T.J. \& Waterman, R.H. (1982). In search of excellence: Lessons from America's best-run companies. New York: Warner Books.

Peters, T.J. \& Austin, N.K. (1985). A passion for excellence: The leadership difference. Great Britain: William Collins.

Peirce, P. (1997). The Intuitive Way. Oregon: Beyond Words Publishing, Inc.

Pierce, J.L. \& Newstrom, J.W. (2003). Leaders \& the Leadership Process. Boston: McGraw-Hill.

Prescott, S. (2000). Realizing the Self Within. Rondebosch: Kima Global Publishers.

Quinn, R.E. (1996). Deep Change. San Francisco: Jossey-Bass Publishers.

Robbins, A. (1992). Awaken the Giant Within. New York: Simon \& Schuster.

Rogers, C.R. \& Sanford, R.C. (1985). Client-centered psychotherapy. In H.I. Kaplan, B.J. Sadock, \& A.M. Friedman (Eds.), Comprehensive textbook of psychiatry (4th $\mathrm{ed}$.) (pp. 1374-1388). Baltimore: William \& Wilkins.

Rosenthal, H.G. (1998). Favorite counseling and therapy techniques. USA: Taylor \& Francis.

Senge, P.M. (1990). The fifth discipline: The art and practice of the learning organization. New York: Doubleday/Currency.

Skiffington, S. \& Zeus, P. (2003). Behavioral Coaching. New York: McGraw-Hill.

Smith, D.P.J. (2005a). Personal and Interpersonal Leadership, Module 1. Johannesburg: University of Johannesburg. (Unpublished 3-day PPL workbook).

Smith, D.P.J. (2005b). Leadership development portfolio. Unpublished manuscript. Johannesburg: University of Johannesburg.

Smith, D.P.J. (2005c). The nature of the Spiritual Dimension. Unpublished lecture. Johannesburg: University of Johannesburg. 
Smith, H.W. (1994). The 10 natural laws of successful time and life management: Proven strategies for increased productivity and inner peace. New York: Warner Books.

Temple-Thurston, L. (2003). The Marriage of Spirit. Santa Fe: CoreLight Publishing.

Thomas, K.W. (2000). Intrinsic motivation at work: Building energy and commitment. San Francisco: Berrett-Koehler Publishers Inc.

Verrier, D.R. (2002). Spiritual fulfilment in a utility company of the City of Johannesburg: A phenomenological study.
Johannesburg: Rand Afrikaans University. (Essay - M.Phil.)

Wilson, R.T. (1998). Servant leadership. Physician Executive, SepOct 1998, (24), 5. (BUSINESS SOURCE PREMIER Database, Ref. No. 1081459)

Witz, P. (1998). One Powerful Mind. Scarborough: Prentice Hall Canada.

Zohar, D. \& Marshall, I. (2000). Spiritual Intelligence. The Ultimate Intelligence. Great Britain: Bloomsbury.

Zohar, D. \& Marshall, I. (2004). Spiritual Capital. Great Britain: Bloomsbury. 


\section{REVIEW PANEL EDITION 3.1}

Prof CB Fouché

Prof CJ Groenewald

Dr Denise Meyerson

Prof Paul Moller

Dr AG Moore

Prof ZJ Nel

Prof C Pottas

Prof MJ Terreblanche

Dr Peter Whitehead

Ms Janine Whitehead

Dr D Wijnbeek
Massey University, New Zealand

University of Stellenbosch

Management Consultants International, Australia

North West University (Potchefstroom Campus)

Dept of National Treasury

Daimler Education Group, Randburg

Emeritus Professor, University of Pretoria

UNISA

Work Dynamics, George

Dept of HRM, Daimler Chrysler

Clover 